\title{
VISUALISASI 3 DIMENSI TUMBUHAN LANGKA DI PUSAT KONSERVASI TUMBUHAN KEBUN RAYA BOGOR
}

\author{
Rubil $^{1}$; Arini ${ }^{2}$; Ardiyan Saputra Syam ${ }^{2}$ \\ ${ }^{1}$ Information Systems Department, School of Information Systems, Binus University \\ Jl. K.H. Syahdan No. 9, Palmerah, Jakarta Barat 11480 \\ rubil@binus.ac.id \\ ${ }^{2}$ Program Studi Teknologi Informasi, Fakultas Sains dan Teknologi, UIN Syarif Hidayatullah \\ Jl. Ir. H. Juanda No. 95, Ciputat, Jakarta 15412 \\ arinizoel@yahoo.com
}

\begin{abstract}
Plants are an important part of the cycle of life, but often overlooked by human existence. Lots of plants are on the verge of extinction so it is difficult to see their figures. Many efforts have been done by agencies to preserve the rare plant. With the 3-dimensional visualization that replaces the figures of the ungrowing plants, the authors intend to make a 3D prototype application of rare plant encyclopedia. The goal is to simplify the users, especially visitors of Plant Conservation Center Library to see 3-dimensional model of rare plants. The application is created through several stages of research, including field observations and interviews, library research, and related researches. Vaughan multimedia development is implemented for system development which has 4 stages. First is planning by searching target audiences, and making design concept of and navigation concept. Next is design and production phase using 5 activities such as storyboard, flowchart, interface design, content search and production. Alpha and Beta testing is used as the testing phase. The last is the multiplication and distribution phase of application deployment. This application can allow users to search for information about the world of plants. For further development of the process, the application is expected to run in a web-based media to be accessible by public.
\end{abstract}

Keywords: encyclopedia, 3 dimensional, 3D modeling

\begin{abstract}
ABSTRAK
Tumbuhan merupakan bagian yang penting dari siklus kehidupan di Dunia, tetapi seringkali keberadaannya diabaikan oleh manusia. Banyak sekali tumbuhan yang diambang kepunahan sehingga sulit untuk dilihat bentuknya. Banyak upaya yang telah di lakukan oleh instansi-instansi yang berusaha menjaga kelestarian dari tumbuhan langka tersebut. Dengan adanya visualisasi 3 dimensi untuk menggantikan bentuk dari tumbuhan yang sedang dalam kondisi tidak tumbuh, penulis bermaksud membuat sebuah aplikasi Prototipe Ensiklopedia Tumbuhan langka 3 Dimensi. Tujuannya adalah untuk mempermudah user atau user khususnya pengunjung Perpustakaan Pusat Konservasi Tumbuhan untuk dapat melihat model 3 dimensi tumbuhan langka. Pembuatan aplikasi ini melalui beberapa tahap, yaitu penelitian lapangan yang meliputi observasi dan wawancara, penelitian kepustakaan, dan studi literatur sejenis. Untuk pengembangan sistem, peneliti menggunakan metode pengembangan multimedia Vaughan yang memiliki 4 tahapan yaitu fase perencanaan aplikasi dengan melakukan target audiens, konsep desain dan konsep navigasi. Pada fase desain dan produksi digunakan 5 aktivitas seperti storyboard, flowchart, desain antarmuka, pencarian isi dan produksi. Alpha dan Beta testing digunakan saat fase pengujian, dan yang terakhir adalah fase distribusi yaitu penggandaan dan penyebaran aplikasi. Aplikasi ini dapat memudahkan user dalam mencari informasi seputar Dunia tumbuhan. Untuk proses pengembangan selanjutnya, diharapkan aplikasi ini mampu berjalan dalam sebuah media berbasis website agar dapat diakses oleh umum.
\end{abstract}

Kata kunci: ensiklopedia, 3 dimensi, 3D modeling 


\section{PENDAHULUAN}

Indonesia merupakan salah satu negara Mega Biodiversity dengan kekayaan akan keanekaragaman hayati ekosistem, sumberdaya genetika, dan spesies yang sangat berlimpah. Tidak kurang dari 47 jenis ekosistem alam yang khas sampai jumlah spesies tumbuhan berbunga yang sudah diketahui, sebanyak $11 \%$ atau sekitar 30.000 jenis dari seluruh tumbuhan berbunga di dunia. Sayangnya, banyak jenis tumbuhan tertentu, mengalami kepunahan. Sampai saat ini, Pusat Konservasi Tumbuhan Kebun Raya Bogor-Lembaga Ilmu Pengetahuan Indonesia (LIPI) serta tiga cabangnya (Kebun Raya Cibodas,Purwodadi, dan Bedugul Bali) baru mengoleksi 20\% total jenis tumbuhan yang ada di Indonesia. Koleksi anggrek kurang dari 5\% yang ada di Kawasan Timur Indonesia. Untuk jenis durian saja, Indonesia memiliki puluhan jenis, talas ada 700-an jenis, yang semuanya sangat potensial untuk dikembangkan.

Namun, kerusakan lingkungan telah menghancurkan banyak habitat-habitat tumbuhan yang menyebabkan punahnya jenis-jenis tumbuhan tertentu. Upaya yang dilakukan Pusat Konservasi Tumbuhan Kebun Raya Bogor telah banyak sekali, mulai dari penanaman kembali benih tumbuhan sampai observasi di beberapa tempat untuk mendapatkan data tumbuhan yang populasinya mendekati batas terancam punah. Selain itu untuk mendukung kegiatan tersebut, dibutuhkan pula sebuah media yang dapat digunakan baik sebagai media penyampaian data informasi maupun sebagai media dokumentasi data terhadap jenis-jenis tumbuhan langka tersebut.

Dalam membantu memenuhi kebutuhan penyimpanan data tumbuhan langka, diperlukan adanya aplikasi multimedia yang berisikan pengenalan berupa Ensiklopedia visualisasi 3 dimensi tumbuhan langka yang ada di pusat Konservasi Tumbuhan di Kebun Raya Bogor. Aplikasi multimedia 3 dimensi tersebut hanya menampilkan empat model tumbuhan langka dari empat divisi tumbuhan yaitu Divisi Thallophyta, Divisi Bryophyta, Divisi Spermatophyta dan Divisi Pteridophyta di mana pembuatan object 3 dimensi dibuat menggunakan teknik high poly.

Tujuan penelitian ini adalah mempermudah user dan pengunjung pusat Konservasi tumbuhan untuk mendapatkan data tumbuhan langka dan juga bertujuan untuk membantu pengenalan teknik komputerisasi dalam menyimpan informasi tumbuhan sehingga memudahkan user mendapatkan informasi seputar dunia tumbuhan.

\section{METODE}

\section{Pengumpulan Data}

Ada beberapa teknik yang digunakan oleh peneliti dalam rangka pengumpulan data. Pertama adalah studi kepustakaan dengan cara membaca dan mempelajari buku-buku dan ebook yang berhubungan dengan informasi tumbuhan langka, pemodelan 3D serta buku-buku maupun artikel yang diperoleh dari media cetak maupun internet untuk mendukung topik yang dibahas. Berikut bebebrapa teori yang telah dirangkum:

\section{Objek 3 Dimensi}

Obyek 3 Dimensi adalah banguan yang tersusun dari beberapa bidang dalam ruang 3 dimensi. Untuk membentuk suatu obyek 3 dimensi. terdapat beberapa elemen dasar yang menyusunnya, yaitu vertex, edge, face, dan texture.

Dalam komputer gratis 3 dimensi. vertex adalah suatu titik yang ada di ruang 3 dimensi dan 
merupakan struktur dasar dalam pembentukan obyek.bagian yang terkecil dari suatu obyek 3 dimensi. Informasi yang disimpan dalam vertex adalah koordinat $\mathrm{x}, \mathrm{y}, \mathrm{z}$ dari titik tersebut.

Edge adalah suatu garis yang ditarik dari dua vertex. Hal ini berarti edge adalah garis yang ada di ruang 3 dimensi. Berbeda dcngan vertex, informasi yang disimpan dalam edge adalah vertex awal dan vertex akhir yang membentuk edge tersebut.

Face adalah suatu bidang yang dibentuk dari 3 vertex. Hal ini berarti face berbentuk segitiga karena dibentuk dari tiga vertex dan berada di ruang 3 dimensi. Informasi yang disimpan dalam face mirip dengan edge, yaitu tiga buah vertex yang membentuknya. Pada dasarnya teknik texture/ tekstur adapah teknik pemberian warna pada objek 3 dimensi, di mana warna tersebut mewakili elemen pada objek aslinya. Dalam komputer grafis, texture adalah gambar yang ditempelkan pada permukaan obyek 3 dimensi. Sedangkan satu texture yang sama dapat dipakai lebih dari satu kali untuk bidang yang berbeda-beda. Suatu texture mempunyai nilai U dan V yang dimulai dari Nol sampai dengan satu. di mana $\mathrm{U}$ adalah bagian yang horisontal sedangkan $\mathrm{V}$ adalah bagian yang vertical.

\section{Proses Perhitungan Perspective}

Fungsi dari bagian ini adalah untuk mengubah koordinat 3 dimesi baru yang sudah dipengaruhi oleh nilai perspektif sehingga semakin jauh benda ataupun objek, objek tersebut akan semakin kecil. Caranya dengan membuat suatu matrix kemudian mengalihkannya dengan matrix koordinat vertex yang diperoleh dari proses perhitungan kamera.

Informasi-informasi yang diperlukan untuk membentuk matrix tersebut adalah sebagai berikut: (1) field of view - berisi informasi mengenai besar dari sudut pandang dari kamera, di mana hanya objek yang ada dalam jangkauan sudut pandang inilah yang akan di proyeksikan; (2) besar aspek rasio - berisi informasi besar perbandingan antara lebar dan tinggi dari hasil proyeksi; (3) kedalaman terdekat (Znear) dan kedalaman terjauh (Zfar) - berisi nilai dari kedalaman terdekat dan kedalaman terjauh yang akan di proyeksikan; semua yang ada diluar area tersebut tidak akan di proyeksikan

\section{Proses Perhitungan Viewport}

Sebagian besar dari penjelasan berikut merupakan teori yang dipakai OpenGL untuk membuat matrix viewport yang dikutip dari fungsi dari bagian ini adalah untuk memproses koordinat dari $\mathrm{X}$ dan $\mathrm{Y}$ yang diperoleh dari bagian sebelumnya hingga didapatkan koordinat X dan Y pada viewport. Yang dimaksud dengan viewport disini adalah suatu daerah tertentu pada layar monitor di mana hasil dari proyeksi ini boleh digambar. Informasi-informasi yang disimpan pada bagian ini adalah: (1) koordinat $\mathrm{X}, \mathrm{Y}$ dari viewport - berisi informasi mengenai paling kiri atas dari viewport; (2) width, height dari viewport - berisi informasi mengenai besar dan tinggi dari viewport.

\section{Teknik Pemodelan 3 Dimensi}

Modelling adalah proses membuat objek dan masa, termasuk di dalamnya berbagai tipe model dan cara pengerjaan pembuatannya (O'Rourke, 2003). Terdapat beberapa macam sistem pemodelan, pilihan tipe modelling bergantung pada apa yang dijadikan model akhir, kemudahan useran, kualitas, dan pengaruh dari kecepatan rendering. Terdapat tiga sistem modelling yang biasa digunakan Polygon Modeller, Spline Modeller dan Patch Modeller .

\section{Transformasi Vertexdengan Morphing}

Dalam pembuatan objek penulis menggunakan teknik Metamorfosis atau morphing tiga 
dimensi merupakan salah satu teknik yang merealisasikan perubahan atau transformasi bentuk suatu obyek menjadi bentuk obyek yang lain. Permasalahan utama dalam melakukan proses morphing pada obyek adalah menentukan korespondensi vertex-vertex pada obyek asal dengan vertex-vertex pada obyek tujuan. Tujuan dari mencari korespondensi permukaan atau vertex antar obyek asal dengan obyek tujuan adalah untuk melakukan mapping setiap vertex dari obyek asal ke obyek tujuan. Dalam proses morphing, posisi vertex pada obyek asal akan berpindah secara bertahap menuju posisi vertex pada obyek tujuan sehingga menyebabkan perubahan bentuk pada obyek asal sampai menjadi bentuk objek tujuan dan kebalikannya (Mark Steyvers, 1999)

\section{Morphing dengan Pembagian Area Obyek}

Untuk mencari korespondensi vertex antar obyek asal dengan obyek tujuan maka dilakukan pembagian obyek asal dan obyek tujuan menjadi beberapa area. Pembagian dilakukan berdasarkan koordinat $\mathrm{x}, \mathrm{y}$ dan $\mathrm{z}$ dari obyek. Pembagian area obyek dilakukan dengan cara membagi dua pada koordinat sumbu $\mathrm{x}, \mathrm{y}$ atau z pada obyek.

\section{Hasil Pengujian Teknik Morphing}

Pengujian dilakukan berdasarkan pembagian area obyek menjadi dua bagian, delapan bagian dan tanpa melakukan pembagian area obyek. Proses morphing tanpa melakukan pembagian area obyek hanya dapat dilakukan pada dua obyek yang memiliki jumlah vertex dan face yang sama. Proses morphing dengan melakukan pembagian area obyek menjadi dua dan delapan bagian hanya dapat dilakukan dengan menggunakan obyek asal memiliki jumlah vertex dan face yang lebih banyak dari obyek asal dan bentuk topologi dari dua obyek hampir sama. Selain studi kepustakaan, dilakukan pula studi lapangan dengan survei ke Kebun Raya Bogor serta pengamatan langsung tentang perbedaan proses penangkapan informasi kepada masyarakat terhadap aplikasi yang dibuat. Metode Observasi ini bertujuan untuk melihat langsung Kondisi Tumbuhan langka dan meneliti Taksonomi yang digunakan untuk membedakan Species yang terdapat pada Kebun Raya Bogor yang merupakan Pusat Konservasi Tumbuhan. Pada observasi ini, peneliti mendapatkan informasi seputar dunia tumbuhan, beberapa di antaranya adalah mengenai klasifikasi yang di terapkan pada Pusat Konservasi Tumbuhan langka yang ternyata di bagi dibedakan menurut Suku dari tiap Species tumbuhan (Onrizal, 2008). Kedua adalah wawancara dengan ibu Sutarsyah S.Sos, MP selaku pengawas Perpustakaan dan Dokumentasi Kebun Raya Bogor. Dengan melakukan wawancara, penulis dapat mengetahui materi apa yang cocok untuk disampaikan seputar Flora langka yang ada di Indonesia

\section{Pengembangan Multimedia}

Untuk pengembangan multimedia, penulis akan menggunakan metode pengembangan multimedia menurut Vaughan (2004, dalam Binanto, 2010) yang terdiri dari empat tahap, yaitu perencanaan, desain dan produksi, pengujian, dan distribusi.

\section{HASIL DAN PEMBAHASAN}

Pembuatan aplikasi ini didasarkan pada empat tahap Vaughan (Iwan Binanto, 2010:264) yaitu perencanaan, desain dan produksi, pengujian dan distribusi.

\section{Perencanaan}

Pada tahap pertama ini penulis menetapkan: (1) target audience - secara garis besar aplikasi ini diperuntukan kepada seluruh pengunjung Pusat Konservasi Tanaman Kebun Raya Bogor yang 
hendak melihat visualisasi tumbuhan dalam bentuk 3 Dimensi dan pengetahuan singkat mengenai tumbuhan dan status kelangkaannya. Aplikasi ini dirancang agar mudah dalam userannya dengan menggunakan tombol navigasi yang di label-kan sehingga user akan secara jelas mengetahui fungsi dari tombol tersebut; (2) konsep desain. Dalam pembuatan background aplikasi penulis berusaha menyelaraskan antara tema desain dan tema aplikasi dengan menggunakan background warna coklat yang berkonsepkan tumbuhan, background dibuat menyerupai ruangan yang dibuat dengan menggunakan 3D yang telah dirender dan didominasi oleh tekstur kayu. Warna yang mendominasi tampilan aplikasi adalah warna coklat dan hitam.Warna coklat dengan tekstur kayu dan kertas digunakan sebagai background konten dari aplikasi, sedangkan warna hitam digunakan untuk animasi transisi pada setiap menu. Tombol menu utama dibuat menyerupai buku Ensiklopedia yang dibuat menggunakan grafik 3 Dimensi, pada tiap tombol bertuliskan judul dari tombol tersebut sehingga memudahkan user dalam menginteraksikan aplikasi ini. Tombol menu utama akan aktif bila didekatkan pada kursor mouse dan akan ada navigasi yang menunjukan tombol apa yang sedang aktif; (3) konsep navigasi (Gambar 1). Aplikasi ini menggunakan struktur navigasi hierarki sehingga apabila ingin menuju menu lain yang berbeda, user harus kembali ke menu utama terlebih dahulu sebelum memasuki menu yang ditujukan. Struktur navigasi pada aplikasi ini tergolong mudah karena tidak memiliki level sub menu yang terlalu banyak. Menu Utama yang terdapat pada aplikasi ini adalah "Beranda”, “Materi”, “Bantuan”, “Tentang Aplikasi”, “dan “Data Tumbuhan”. Apabila user mengaktifkan menu utama, maka akan tampil halaman menu utama yang membahas beberapa hal penyebab punahnya tumbuhan langka dan penyebab tumbuhan tergolong langka. Apabila user ingin menuju menu lainnya, user diharuskan untuk menutup menu sebelumnya sebelum masuk pada menu yang dituju, beberapa menu menggunakan struktur navigasi yang sama. Hanya saja sedikit berbeda dengan menu "Data Tumbuhan". Apabila user mengaktifkan menu "Data Tumbuhan" user akan ditujukan kepada halaman yang berisikan beberapa contoh dari tumbuhan langka, pada halaman ini terdapat video Tumbuhan 3D yang difungsikan untuk memvisualisasikan bentuk fisik dari bagian luar tumbuhan. Adapula keterangan tentang tumbuhan tersebut dan tombol yang dihubungkan dengan website "IUCN Redlist" untuk melihat data tumbuhan secara jelas.

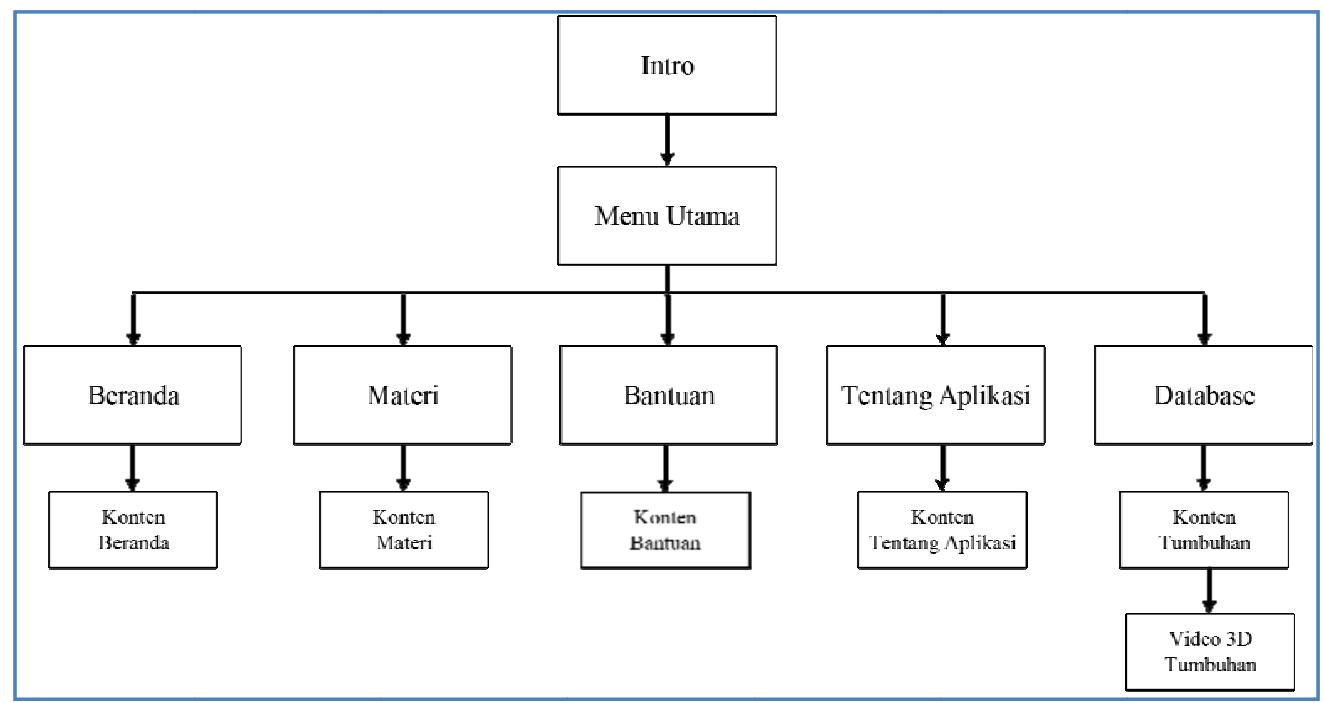

Gambar 1 Konsep struktur navigasi

\section{Desain dan Produksi}

Dalam tahap ini penulis melakukan pembuatan storyboard, struktur navigasi, mendesain interface (antarmuka), pengumpulan dan pencarian isi, assembly dan produksi. 


\section{Storyboard}

Storyboard merupakan deskripsi tiap scene (tampilan), dengan mencantumkan semua objek multimedia dan link ke scene lain (Suyanto, 2003: 375).

\section{Flowchart}

Perancangan flowchart menggambarkan tahapan proses dari suatu sistem, termasuk sistem multimedia (Suyanto,2003:364).

\section{Mendesain Antarmuka (Interface)}

Rancangan antarmuka pemakai (user interface) yang akan ditampilkan pada aplikasi multimedia ini akan disesuaikan dengan kebutuhan user dan pengetahuan user.

\section{Pengumpulan/ Pencarian Isi}

Pegumpulan/ pencarian isi (bahan) berupa File-File audio, video, gambar, foto, teks dilakukan dengan cara mengambil dari berbagai sumber dan membuatnya sendiri. Bahan yang berupa File gambar di ambil dari koleksi pribadi. File audio penulis mendapatkannya dari internet. Sedangkan Filevideo, animasi, dan 3D dibuat sendiri.

\section{Produksi}

Merupakan tahapan untuk mengolah seluruh data yang telah tersedeia serta membuat estimasi kebutuhan perangkat dalam pengerjaan serta menerapkan konsep-konsep yang mendasari pembuatan aplikasi.

Dalam pembuatan model 3Dimensi penulis menggunakan teknik-teknik sebagai berikut: Polygon Modeling - dalam tahap ini penulis menggunakan model awal box yang telah disediakan oleh aplikasi 3D max, objek box diconversi menjadi editable poly agar mudah dirubah bentuknya. Pada pembuatan 3 dimensi tumbuhan penulis mencari referensi gambar objek nyata dari internet, ini di sebabkan karena beberapa tumbuhan yang akan di bahas dalam program dalam kondisi "tidak tumbuh” di Kebun Raya Bogor. Setelah mendapatkan gambar (Gambar 2), penulis memasukan gambar tersebut kedalam aplikasi 3D Max 2009 dan menempelkannya pada sebuah bidang rata (Plane).

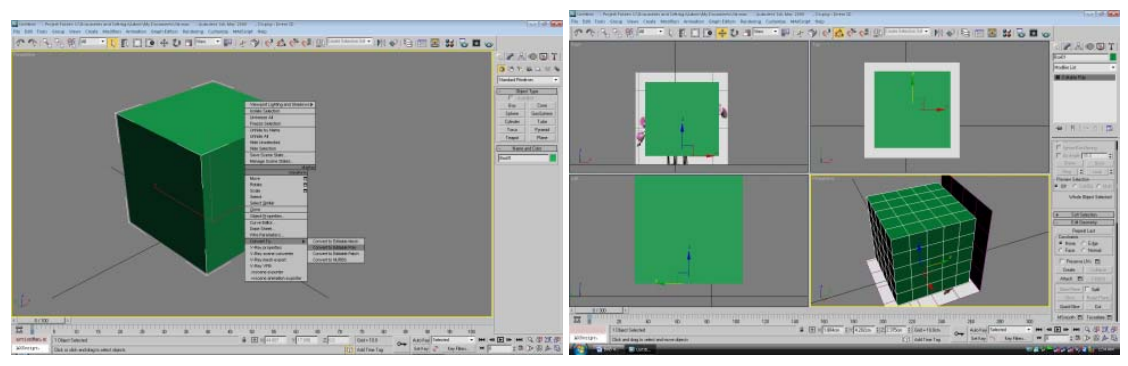

Gambar 2 Hasil proses membuat objek polygon

Transformasi objek - vertex-vertex pada objek polygon ditransformasikan dengan teknik scaling, rotation dan translation yang dilakukan secara bergantian dan terus menerus sampai membentuk objek seperti aslinya (Gambar 3). Translation dapat dilakukan dengan keseluruhan, 
sebagian maupun salah satu dari objek dan vertex. Translation berfungsi untuk memindahkan vertex maupun objek poly untuk mendapatkan bentuk yang dibutuhkan.

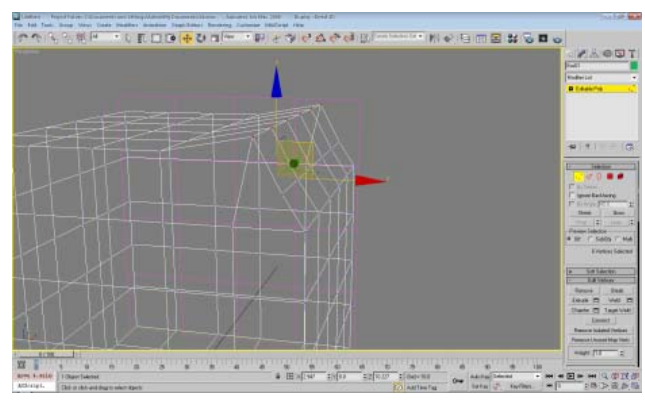

Gambar 3 Hasil proses transformasi objek

Scaling (Gambar 4) dilakukan untuk mengubah ukuran suatu objek, scaling dapat dilakukan terhadap vertex maupun objek secara keseluruhan atau satu per satu.

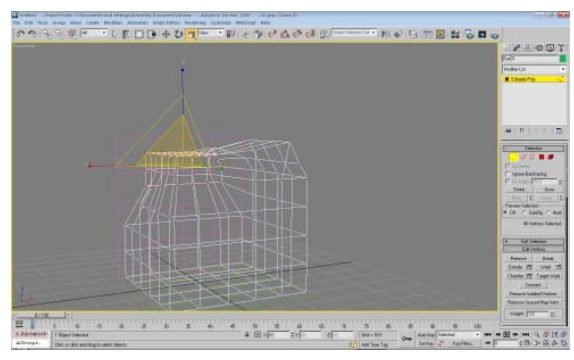

Gambar 4 Hasil proses scaling object

Rotation (Gambar 5) digunakan untuk memutar vertex maupun objek yang dikehendaki, rotation pada suatu vertex akan berpengaruh pada vertex yang berhubungan.

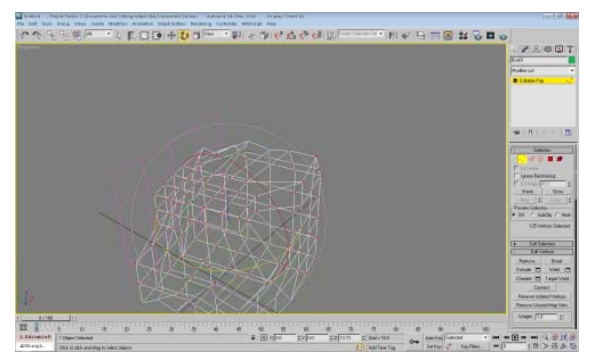

Gambar 5 Hasil proses rotation object

Morph (Gambar 6) digunakan pada objek 3D untuk mendapatkan perubahan secara berkala mengikuti perubahan bentuk dari objek 3D yang ditentukan, morph pada suatu objek hanya bisa dilakukan terhadap objek duplikatnya dengan kata lain morph hanya mampu dilakukan terhadap objek sejenis yang memiliki jumlah vertex dan id objek yang sama. 


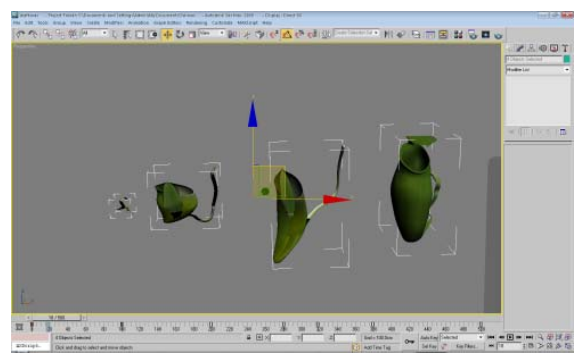

Gambar 6 Hasil proses morph objek

Grow FX (Gambar 7) - transformasi berikutnya yang menggunakan bantuan dari peramban bawaan 3D adalah Modifiergrowplugins atau peramban bawaan ini di unduh dengan gratis namun memiliki 30 hari masa percobaan, fungsi dari peramban ini adalah mampu menghasilkan efek perubahan transisi pada objek, namun berbeda dengan morph yang bergantung pada objek id dan jumlah vertex yang harus sama dengan objek duplikatnya, plugins grow memberikan kebebasan dalam mengatur parameter objek tanpa harus di duplikat sebelumnya sehingga tidak membengkakan ukuran dari file. Kekurangan dari plugins ini adalah kita tidak mampu membuat objek yang kompleks karena plugins ini memang dibuat khusus untuk tumbuhan. Kelemahan berikutnya plugins ini merupakan object helper sehingga tidak dapat ditambahkan modifier hairand fur.

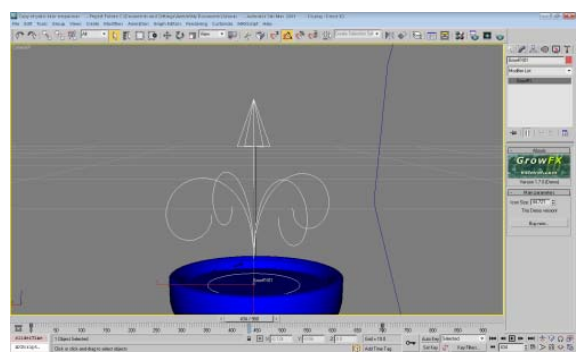

Gambar 7 Hasil proses grow FX

Pemberian tekstur dan material - proses pemberian material pada rangka ini menetukan karakteristik sebuah material objek dari segi texture. Texture bisa digunakan untuk membuat berbagai variasi warna, tingkat kehalusan atau kekasaran sebuah lapisan objek secara detail. Untuk mengakses material, tekan $\mathrm{M}$ untuk memunculkan material editor. Kemudian pilih slot map yang kosong lalu klik kotak abu-abu disamping pilihan difuse. Lalu pilih bitmap, browse dan pilih material rangka yang digunakan. Kemudian tarik material slot ke arah permukaan layar rangka. Penulis memberikan material pada objek dengan material menggunakan adobe photosop CS3. Dan mengintegrasikan dengan beberapa efek Render yaitu V-ray. Dalam proses mapping atau pemberian tekstur, penulis menggunakan modifier map scaler terhadap semua objek yang dibuat.

Proses pembuatan latar belakang objek - pada roses ini penulis menambahkan latar belakang Objek 3 dimensi agar tidak terlihat kosong. Dengan menambahkan objek dinding dan lantai.

Pembuatan animasi 3D - animasi yang buat seluruhnya dengan menggunakan aplikasi 3D max 2009. Dimungkinkan untuk menghidupkan posisi, rotasi dan skala dari suatu objek, dan hampir semua pengaturan parameter yang mempengaruhi bentuk benda dan permukaan. Untuk membuat animasi 3D diawali dengan menentukan panjang durasi animasi per frame pada time configuration. Penulis disini menggunakan 300 frame mengisi end time dengan 300 dengan pertimbangan agar video yang di render tampak halus ketika di putar. 
Proses Rendering (Gambar 8) - ini adalah proses akhir dari keseluruhan proses permodelan ataupun animasi komputer. Dalam rendering, semua data yang sudah di masukan dalam proses modeling, animasi, teksturing tertentu akan di terjemahkan dalam sebuah bentuk output. Pada apliaksi ini menggunakan standar sistem NTSC dengan pertimbangan hasil video yang dihasilkan akan lebih halus, dengan resolusi sebuah render adalah 640 x 480 pixels.

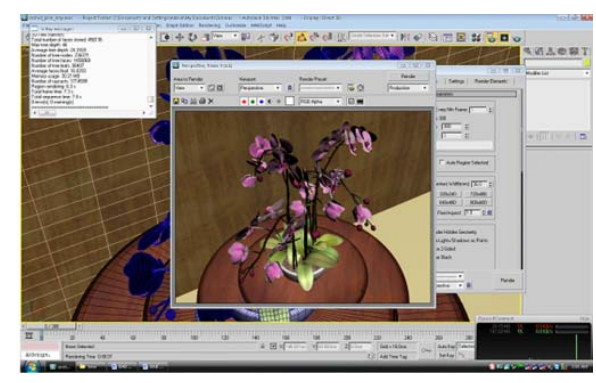

Gambar 8 Hasil proses rendering

Pada proses renderasi penulis merender ke File .Avi (Audio Video Interleave). Pilih File pada menubar kemudian buka scroll Assign Renderer masukan V-Ray Demo 1.5. SP2 kemudian klik render. Keuntungan dari useran efek $V$-Ray adalah mampu menghasilkan efek bayangan sehingga Objek dapat terlihat lebih hidup dibanding dengan proses render biasa

Pembuatan Interface. Pertama, mengatur ukuran frame yang digunakan dalam hal ini penulis menggunakan ukuran layar 800x600 pixel dengan pertimbangan agar layar tidak terpotong ketika digunakan pada komputer dengan ukuran tersebut ataupun diatasnya. Penulis menggunakan latar belakang berwarna hitam agar tidak terlihat potongan ketika aplikasi dibuka dengan layar monitor yang tidak sesuai ukuran. Kedua, memasukan file yang dibutuhkan - pada proses ini penulis memasukan file-file yang dibutuhkan untuk membuat tampilan antarmuka. Secara teori dalam proses ini penulis mendapat bantuan dari pihak staf Kebun Raya Bogor agar tampilan yang dihasilkan sesuai dengan keinginan namun tidak menghilangkan nilai estetika dari sebuah desain. Ketiga, mengatur tata letak design - pada proses ini penulis mengatur semua tata dan letak file gambar yang akan dimasukan dan membaginya menjadi beberapa layer sesuai dengan fungsinya untuk memudahkan pemberian ActionScript 2 (AS2). Keempat, membuat movie clip - setelah file gambar yang dibutuhkan dimasukan dan diatur posisinya, proses berikutnya adalah mengkonversi beberapa gambar kedalam movie clip agar mudah dianimasikan dan diberikan suatu fungsi tertentu. Kelima, menambah Frame pada proses ini penulis menambahkan frame dengan cara mengkonversi frame kosong pada timelineAdobe flash menjadi frame aktif dengan cara Insert Frame. Keenam, memberikan ActionScript 2 (Sutopo, Ariesto Hadi:2002) - setelah semua data telah masuk dan telah diatur letak frame serta timeline-nya penulis memberikan Action Script 2 pada beberapa Movie clip dan tombol agar bisa berinteraksi dengan cursor mouse ketika di klik.

\section{Pengujian}

Pengujian (testing) dilakukan terhadap program aplikasi yang tekah dibuat. Pengujian pertama dilakukan secara modular untuk memastikan apakah hasilnya seperti yang diinginkan yaitu secara alpha testing, di mana menurut International Software Testing Board (2005) bahwa alpha testing adalah "simulasi atau ujicoba aktual yang dilakukan oleh potensial user atau tim penguji independen yang berasal dari tim pengembang aplikasi”. Pengujian selanjutnya dengan metode beta, yaitu "pengujian operasional yang dilakukan oleh user yang berasal dari luar dan tidak terlibat dengan proses pengembangan aplikasi, yang bertujuan untuk memutuskan apakah aplikasi yang dibuat sudah sesuai dengan kebutuhan user dan kebutuhan bisnis” (International Software Testing Board, 2005) . 


\section{Pengujian Alpha}

Yang diuji adalah fungsi-fungsi khusus dari aplikasi yang dirancang. Kebenaran aplikasi yang diuji hanya dilihat berdasarkan keluaran yang dihasilkan dari data atau kondisi masukan yang diberikan untuk fungsi yang ada tanpa melihat bagaimana proses untuk mendapatkan keluaran tersebut. Dari keluaran yang dihasilkan, kemampuan program dalam memenuhi kebutuhan pemakai dapat diukur sekaligus dapat diiketahui kesalahan-kesalahannya.

\section{Pengujian Beta}

Merupakan pengujian yang dilakukan secara objektif di mana dilakukan pengujian langsung ke lapangan di Kebun Raya Bogor untuk masyarakat luas dan tidak terbatas hanya pada kalangan tertentu saja. Pengujian ini dilakukan untuk mengetahui pendapat responden terhadap Aplikasi ini.

\section{Distribusi}

Setelah melakukan pengujian tahap yang terakhir adalah distribusi. Tahap ini merupakan Tahap penggandaan dan penyebaran aplikasi kepada Staf Kebun Raya Bogor. Penggandaan aplikasi dapat dilakukan dengan menggunakan CD-RW. Aplikasi ini didistribusikan agar dapat digunakan sebagai media penyimpanan data tumbuhan langka yang berada di Indonesia dan dapat digunakan tidak hanya untuk tumbuhan saja, tentunya dengan mengubah sedikit desain dan tema.

\section{PENUTUP}

Dalam pembuatan aplikasi visualisasi 3 dimensi tumbuhan langka di Kebun Raya Bogor digunakan konsep seperti modeling 3D dan pembuatan interface sehingga didapatkan model tumbuhan 3D yang mewakili tumbuhan aslinya. Selain itu aplikasi tersebut sudah mampu menampilkan perubahan bentuk yang merupakan fase dari tumbuhan yang dibuat model 3D nya.Aplikasi visualisasi 3D tumbuhan tersebut, membantu memenuhi kebutuhan penyimpanan data tumbuhan langka yang ada di Kebun Raya Bogor sehingga user dan pengunjung dengan mudah mendapatkan informasi seputar dunia tumbuh-tumbuhan khususnya tumbuhan langka.

Pembuatan aplikasi visualisasi 3 dimensi tumbuhan langka di Kebun Raya Bogor ini adalah salah satu cara dalam penyampaian informasi dan media penyimpanan data terkait tumbuhan yang ada di Kebun Raya Bogor, namun kedepannya akan lebih baik jika aplikasi ini dapat digunakan dalam media website sehingga dapat diakses dengan mudah dari internet. Selain itu diharapkan agar klasifikasi tumbuhan yang dibahas pada aplikasi ini diperluas dan pembuatan model 3D dikembangkan dengan menggunakan teknik lain.

\section{DAFTAR PUSTAKA}

Binanto, Iwan. (2010). Multimedia Digital Dasar Teori dan Pengembangannya. Yogyakarta: Penerbit Andi.

International Software Testing Board. (2005) Standard glossary of terms used in Software Testing (version 1.1). Glosary Working Party, International Software Testing Board. Diakses dari http://www.cftl.fr/fileadmin/pdf/en/glossary-current_v1.1.pdf. 
Materi perkuliahan tidak diterbitkan. Departemen Kehutanan Universitas Sumatra Utara, Medan. Diakses dari http://onrizal.files.wordpress.com/2008/10/kul-6-8.pdf.

O'Rourke, Michael. (2003). The Principles of Three-Dimensional Computer Animation: Modelling, Randering and Animating with 3D Graphics (3rd ed.). New York: WW Norton \& Company Incorporated.

Onrizal (2008). Klasifikasi Tumbuhan.

Steyvers, Mark. (1999). Morphing techniques for manipulating face images. Behavior Research Methods, Instruments, \& Computers 1999, 31 (2), 359-369. Diakses dari http://psiexp.ss.uci.edu/research/papers/brmic.pdf.

Sutopo, Ariesto Hadi. (2002). Animasi dengan Macromedia Flash Berikut ActionScript. Jakarta: Salemba Infotek.

Suyanto. (2005). Multimedia Alat untuk Meningkatkan Keunggulan Bersaing. Yogyakarta: Andi Offset.

Vaughan, Tay. (2004). Multimedia. Making It Work (6th ed.). New York: McGraw Hill. 